\title{
Hypothalamic-Pituitary-Adrenocortical (HPA) Axis Response and Biotransformation of Oral Naltrexone: Preliminary Examination of Relationship to Family History of Alcoholism
}

\author{
Andrea C. King, Ph.D., James Schluger, M.D., Mithat Gunduz, M.S., Lisa Borg, M.D., \\ Guillaume Perret, M.D., Ann Ho, Ph.D., and Mary Jeanne Kreek, M.D.
}

We examined HPA axis response to $50 \mathrm{mg}$ oral naltrexone compared with placebo in 17 healthy male and female nonalcoholic subjects, approximately half of whom had a positive family history of alcoholism $(\mathrm{FH}+$ ) and half of whom who did not (FH-). Mood response and naltrexone biotransformation were also examined at various intervals. Subjects participated in two morning test sessions $(50 \mathrm{mg}$ naltrexone or identical placebo pill) after an overnight stay in the Rockefeller University GCRC. For the total sample, ACTH and cortisol significantly increased after naltrexone compared with placebo $(\mathrm{p}<.05)$. Secondary analyses showed the FH+ subgroup had a different pattern of response over time compared with the $\mathrm{FH}$ - subgroup, with heightened ACTH and cortisol, and decreased vigor ratings, during naltrexone $(\mathrm{p}<.05)$. The results demonstrate that orally administered naltrexone acutely disinhibits the HPA axis, and that individuals with an assumed greater biological vulnerability to addiction, by virtue of familial alcoholism, had altered regulation of the HPA axis in part under the control of the endogenous opioid system. 166 words.

[Neuropsychopharmacology 26:778-788, 2002] (c) 2002 American College of Neuropsychopharmacology. Published by Elsevier Science Inc
KEY WORDS: Naltrexone; 6 - $\beta$-naltrexol; Opioid antagonist; HPA axis; ACTH; Cortisol

The endogenous opioid system plays a role in the modulation of the hypothalamic-pituitary-adrenal (HPA) axis (Cushman and Kreek 1974; Johnson et al. 1992; Kreek 1972, 1973, 1978). Opioid antagonist administration blocks

From the University of Chicago, Department of Psychiatry, Chicago IL 60637 (ACK), and Rockefeller University, Laboratory of the Biology of Addictions, New York, NY 10021 (ACK, JS, MG, LB, GP, $\mathrm{AH}, \mathrm{MJK})$.

Address correspondence to: Andrea King, Ph.D., University of Chicago, Dept. of Psychiatry, 5841 S. Maryland Avenue (MC-3077), Chicago, IL 60637, Tel.: (773) 702-6181, fax (773) 702-6454, E-mail: aking@yoda.bsd.uchicago.edu

Received May 23, 2001; revised October 23, 2001; accepted November 12, 2001.

Online publication: 11/20/01 at www.acnp.org/citations/Npp 112001208 the tonic opioid inhibition of HPA axis activity, thereby resulting in release of POMC-derived hormones in the pituitary and cortisol from the adrenal gland. Indeed, numerous studies have demonstrated acute increases in adrenocorticotropin (ACTH) and cortisol levels in man after intravenous infusion of the opioid antagonists naloxone (Cohen et al. 1983; Conaglen et al. 1985; Delitala et al. 1994; Kreek et al. 1984; Naber et al. 1981; Martin del Campo et al. 1994; Morley et al. 1980; Schluger et al. 1998; Volavka et al. 1979a) and nalmefene (Schluger et al. 1998). However, few studies have examined acute neuroendocrine response to the opioid antagonist naltrexone, which, in contrast to naloxone and nalmefene, is not available for intravenous administration.

The two published studies on the acute HPA axis effects of orally administered naltrexone have both been conducted with relatively small sample sizes $(n \leqslant 10)$. 
The first study (Volavka et al. 1979b), conducted in ten normal male subjects, showed that oral naltrexone significantly increased cortisol levels two hours after administration and directionally (but nonsignificantly) increased ACTH levels one hour after administration. However, due to the small sample studied, the power may not have been sufficient to detect differences. The results may also have been confounded by the co-occurrence of pain sensitivity testing (i.e., 2-min cold pressor task) during the protocol, which may have produced independent HPA axis responses. A more recent study in six abstinent alcoholic patients (Farren et al. 1999) showed significant increases in cortisol and ACTH to three doses of oral naltrexone $(25,50$, and $100 \mathrm{mg})$ with no dose-dependent effects (Farren et al. 1999).

It has been hypothesized that alterations in HPA axis function may play a role in various stages of addiction, including initiation, maintenance, and relapse (Kreek 1992). Naltrexone (50 mg oral) has shown efficacy in the treatment of alcohol dependence (Volpicelli et al. 1992, 1997; O'Malley et al. 1992; Anton et al. 1999), which led to its FDA-approval for adjunctive treatment of alcoholism. Studies examining HPA axis response after oral naltrexone administration might be of potential clinical relevance as neuroendocrine changes and sensitivity to naltrexone could relate to individual differences and treatment response. Hypothetically, the effects of an opioid antagonist, such as naltrexone, in modulating tonic inhibition of the opioid system at various receptors, including primarily $\mu$, but also $\delta$ and $\kappa$, may relate to treatment response and its association with stress responsive opioid activity. Prior collaborative studies by our group have indicated that heroin addicts show continued elevated HPA hormone levels during intermediate-term treatment with daily oral naltrexone (Kosten et al. 1986a, 1986b). Therefore, continued investigation of acute and long-term neuroendocrine response to oral naltrexone, the only available opioid antagonist for opioid and alcohol dependence treatment, may help elucidate the role of the stress responsive endogenous opioid system in these processes.

Most previous studies in this area have examined HPA axis response to intravenous naloxone and have shown a relatively large variability in subjects' hormonal response to opioid antagonists. One important individual difference factor in sensitivity of the HPA axis to naloxone administration may be the presence of a positive family history of alcoholism $(\mathrm{FH}+)$. Indeed, $\mathrm{FH}+$ subjects have shown altered neuroendocrine responses to a variety of agents, including acute administration of alcohol (Gianoulakis et al. 1989, 1996; Schuckit et al. 1987; Schuckit \& Gold 1988; Schuckit et al. 1988), ovine corticotropin releasing factor (o-CRF) (Waltman et al. 1994), and biobehavioral stressors (Peterson et al. 1996). Studies examining sensitivity to intravenous naloxone infusion have also shown similar differential HPA response based on the presence of biological fam- ily history for alcoholism compared with no family history for alcoholism (FH-) (Wand et al. 1998, 1999a, 2001). One study demonstrated maximal hormonal response in $\mathrm{FH}+$ compared with $\mathrm{FH}-$ at a relatively low dose of naloxone $(125 \mu \mathrm{g} / \mathrm{kg})$, independent of plasma naloxone concentrations. However, this finding is not ubiquitous as another study by the same group (Wand et al. 2001) showed FH effects only at higher naloxone doses (375 to $500 \mu \mathrm{g} / \mathrm{kg}$ ).

Finally, in contrast to naloxone, naltrexone is orally administered, has a longer duration of action (i.e., half life $4-5 \mathrm{~h}$ vs. $1-2 \mathrm{~h}$ for naloxone), and is extensively metabolized in the liver by glucuronidation (see Gonzalez and Brogden 1988). Prior studies have indicated levels of naltrexone and its active metabolite, 6- $\beta$-naltrexol, peak in blood 1.5 hours after administration, but reports range from $1-10 \mathrm{~h}$, most likely due to individual subject differences, timing of sampling, and other methodological differences. The extent of naltrexone biotransformation to 6- $\beta$-naltrexol also may determine some aspects of medication response, such as incidence of side effects (King et al. 1997a) or acute response to alcohol (McCaul et al. 2000). Naltrexone has been shown to produce modest mood changes in humans, including mild sedation, headaches, and nausea (Mendelson et al. 1978; King et al. 1997b). The significance of naltrexone metabolism with respect to neuroendocrine changes, or mood effects, has yet to be determined.

Therefore, the aims of the present study were: (1) to determine the acute neuroendocrine and mood response to oral naltrexone in healthy normal volunteers; (2) to examine neuroendocrine and mood response to oral naltrexone as a function of biological family history of alcoholism, as a preliminary extension of the findings of Wand et al. (1998, 1999a); and (3) to examine the association of serum naltrexone and 6- $\beta$-naltrexol levels with HPA axis and subjective response after oral naltrexone administration. Based on the presumed neurobiological pathways involved (antagonist blockade of central tonic opioid inhibition on hypothalamic-pituitary activity) and prior studies with naloxone infusion, we hypothesized that naltrexone compared with placebo administration would acutely increase subjects' ACTH and cortisol response and that $\mathrm{FH}+$ subjects would show greater opioid antagonism sensitivity (i.e., as measured by stress hormone increases) to orally administered naltrexone than $\mathrm{FH}$ - subjects. We also predicted that these effects would be independent of drug disposition or mood changes after naltrexone administration.

\section{METHODS}

\section{Subjects}

Participants were healthy male and female social drinkers between the ages 23 and 47, recruited by local area 
newspaper advertisements and flyers. Exclusion criteria included a history of alcohol or substance dependence or frequent use of drugs other than alcohol (i.e., recurrent monthly or greater), psychiatric or medical disorders, clinically significant abnormalities on screening laboratory tests (SGOT, GGTP, bilirubin, etc.), or a positive urine drug screen (amphetamines, barbiturates, opiates, cocaine). Two subjects were current smokers (one $\mathrm{FH}+$, one $\mathrm{FH}-$ ) but smoked five or fewer cigarettes daily with no signs of nicotine dependence (Fagerström scores $\leqslant 2$ (Heatherington et al. 1991)). Women candidates who were postmenopausal or taking birth control pills were excluded due to potential alterations in neuroendocrine function. Also, individuals who were adopted or uncertain about primary and secondary relatives' substance use patterns were excluded from participation. Study procedures met American Psychiatric Association ethical standards and were approved by the Rockefeller University Institutional Review Board. Subjects were compensated (\$150 payment) at the end of participation.

Eighteen subjects were eligible and enrolled in the study. One female subject completed the first session but catetharization and blood sampling were problematic, so the second session was cancelled, leaving a total of 17 subjects completing the study. Secondary analyses examined 15 of these subjects who were divided into two subgroups, based on positive $(\mathrm{FH}+)$ or negative $(\mathrm{FH}-)$ family history for alcohol dependence. The FH+ subgroup ( $\mathrm{n}=8 ; 5$ males, 3 females) consisted of those subjects reporting alcohol dependence in either one or both biological parents or three or more biological secondary relatives. The FH- subgroup $(\mathrm{n}=7 ; 4$ males, 3 females) consisted of those persons with no history of alcohol dependence in at least the past two generations. Two subjects in the overall sample (2 females) were of intermediate family history status (i.e., one secondary family member with alcohol dependence) and therefore excluded from these secondary family history subgroup analyses.

\section{Procedure}

Subjects were screened by an interview conducted by the study psychologist (A.K.) and physical examination conducted by the study physicians (J.S., G.P.). Those persons who met the inclusion criteria and were of good general physical and mental health were asked to participate in two consecutive testing sessions at the Rockefeller University General Clinical Research Center (GCRC). The protocol was approved by the Rockefeller University Institutional Review Board. Before participating in the study, subjects read and signed the consent form. Subjects were instructed to refrain from alcohol at least $24 \mathrm{~h}$ prior to testing and each subject was tested individually. Attempts were made to test fe- male subjects during the follicular phase of the menstrual cycle, based on subject self-report of their last menstrual cycle.

The subject arrived at the GCRC at approximately 7 P.M. the evening prior to the study and the two testing sessions were conducted on the following two mornings. The sessions were identical except for administration of $50 \mathrm{mg}$ oral naltrexone or identical placebo pill. Upon admission to the GCRC, vital signs and a breathalyzer test were administered. All breathalyzer tests were negative for alcohol in this sample. The subject was allowed to relax and read or watch television in his/her own private, stress-minimized room at the GCRC and lights were turned out by midnight. On the following morning at 8 A.M., the study nurse gave the subject a light breakfast (English muffin, jelly or jam, apple juice) which was followed by insertion of the intravenous catheter (approximately 8:20 A.M.). The next 30-40 $\mathrm{min}$ consisted of a rest period to allow adaptation to the catheter.

At 9 A.M., the baseline blood sample (0 time point) was taken, immediately followed by ingestion of the 50 mg. naltrexone capsule. Each subject also completed questionnaires, including the short version of the Profile of Mood States (POMS; McNair et al. 1971; Schacham 1983), a side effects questionnaire (Volpicelli et al. 1992; King et al. 1997a), and the Alcohol Urge Questionnaire (Bohn et al. 1995). These questionnaires were repeated at two post-capsule intervals (90 and $240 \mathrm{~min}$ ). Blood sampling continued at regular post-capsule intervals $(30,60,90,120,150,180$, and $240 \mathrm{~min})$. Additional 8- and 11-h post-capsule blood samples were drawn the evening of the first testing session. The study was double-blind as both the research study nurse and the subject were blind as to the content of the pill. However, for purposes of measuring biotransformation over $24 \mathrm{~h}$ after administration, the order for capsule administration was fixed, with naltrexone administered on day 1 and placebo on day 2 for all subjects.

While not completing questionnaires or other measures, the subject was allowed to relax and either read or watch videotapes or television. To reduce the potential confounds of hunger, which might alter HPA axis function, a light meal was given approximately 1.5 hours after the capsule administration (approximately 1045) and a lunch was given at the end of the session (after the 240 min blood draw). At the end of the second session, subjects were debriefed and given an exit interview.

\section{Subjective Scales}

During screening, family history determinations were made based on the subjects' self-report on the Brief Michigan Alcoholism Screening Test (B-MAST-10; Pokorny et al. 1972) for self and primary relatives, and a twogeneration family tree for both primary and secondary 
biological relatives. The validity of offspring reports for familial drinking practices has been previously established (Levenson et al. 1987; O'Malley et al. 1986; Sher and Descutner 1986). Other questionnaires administered during screening included the Structured Clinical Interview for DSM-IV Disorders (SCID) Substance Use Disorders Module E (First et al. 1995), the Quantity-Frequency Interview (QFI; Cahalan et al. 1969), and the CAGE test (Ewing 1984). Standard cut-off thresholds were used for these instruments to rule out past or current drug or alcohol abuse and dependence.

The subjective questionnaires given during the testing sessions (i.e., at 0,90 , and $240 \mathrm{~min}$ ) were the 37 -item shortened version of the POMS, the AUQ, and the naltrexone side effects questionnaire. The POMS consists of six main subscales: vigor, fatigue, anxiety, depression, anger, and confusion. The side effects questionnaire has been used in previous clinical and preclinical studies of naltrexone and consists of ratings $(0=a b-$ sent; 1 = mild; 2 = severe) for commonly-noted side effects of naltrexone, including headache, anxiety, nausea, vomiting, sexual desire, and erection. The AUQ is an 8-item scale that has been shown to be sensitive to urge to consume alcohol (Bohn et al. 1995).

\section{Biological Samples}

Blood samples were drawn into sodium EDTA vacutainer tubes and stored on ice immediately. Samples were centrifuged at $4^{\circ} \mathrm{C}$ at $3000 \mathrm{rpm}$ for $5 \mathrm{~min}$. Plasma was then removed, aliquoted, and stored at $-40^{\circ} \mathrm{C}$ until assayed. Assays were conducted in duplicate at the Rockefeller University Laboratory of the Biology of Addictive Diseases. Techniques followed standard double antibody radioimmunoassay kits with slight modifications for cortisol (Diagnostic Products Corporation, Los Angeles, CA) and ACTH (Nichols Institute, San Juan Capistrano, CA). Intra-assay coefficients of variation were for $9.4 \%$ for $\mathrm{ACTH}$ and $2.9 \%$ for cortisol; interassay coefficients of variation were $15.1 \%$ for $\mathrm{ACTH}$ and $6.0 \%$ for cortisol.

Samples were analyzed for naltrexone and its major metabolite 6- $\beta$-naltrexol by HPLC using an electrochemical detector. Nalbuphine was used as an internal standard to correct for any analyte loss during extraction. The HPLC system (Waters WISP 712, Milford, MA) consists of a Coulochem 5100A electrochemical detector with one conditioning cell model 5021 and one analytical cell model 5011 (ESA, Bedford, MA). A guard cell is also installed to oxidize the impurities presented in the samples. The output of the detector is digitized by a 35900 interface (Hewlett-Packard, Melville, NY) and the HPLC system is operated by a computer (Gateway 2000, 4DX2/50, North Sioux, SD) for data acquisition.
A hydrodynamic voltammogram was constructed to ensure maximum sensitivity by keeping the first detector at 0 and by increasing the second detectors potential for each injection. The detector conditions were: detector 1 potential $+0.3 \mathrm{~V}$ and detector 2 potential $+0.65 \mathrm{~V}$, with the guard cell set at $-0.3 \mathrm{~V}$. The detector response time was $10 \mathrm{~s}$. A phenyl steel column was used for the chromatography $(3.9 \mathrm{~mm} \times 150 \mathrm{~mm})$ and the flow rate was $0.7 \mathrm{~mL} /$ minute at isocratic condition. The mobile phase consisted of $18 \%$ acetonitrile, UV grade, $5 \mathrm{mM}$ sodium pentanesulfonic, monohydrate and $0.0045 \%$ orthophosphoric acid-82\%(v/v) (HPLC grade, Fisher Scientific) and $82 \%$ distilled, deionized water. The standards and samples were extracted using solid phase extraction. The 1-mL cynopropyl cartridges were activated by $1 \mathrm{~mL}$ of acetonitrile followed by $1 \mathrm{~mL}$ of water. The standard and samples were loaded and were eluted by applying a vacuum. The cartridges were washed three times with $1 \mathrm{~mL}$ of water followed with elution of $60 \%$ acetonitrile. The samples and standard were dried with a speed vacuum and the samples were reconstituted with the mobile phase and analyzed by HPLC. The samples were quantified by generating standard curve fitting with linear regression. To assure integrity and quality of the data, quality control samples were prepared from a different source of analytes and were conducted in each sample run. There was $\sim 70 \%$ recovery for naltrexone and 6- $\beta$-naltrexol. Recovery was corrected by taking the peak areas of both naltrexone and 6- $\beta$-naltrexol divided by the internal standard (i.e., nalbuphine) peak area for the standards, unknown samples, and quality control samples. There was a $10 \%$ interassay coefficient of variation and the dynamic range for the assay was 3.12 to $200 \mathrm{ng} / \mathrm{mL}$

\section{Statistical Analyses}

Groups were compared on the major demographic variables by one-way analyses of variance (ANOVAs). Repeated measures ANOVAs were conducted on the neuroendocrine and subjective data, with time and medication as the within-subjects factors. For biotransformation data, repeated measures ANOVAs were conducted with time as a within-subjects variable. Where appropriate, simple effects tests were conducted for significant main effects or interaction effects terms.

For the analyses examining HPA axis response to naltrexone in the $\mathrm{FH}+/ \mathrm{FH}-$ subgroups, the neuroendocrine data was also analyzed by similar repeated measures ANOVA with group $(\mathrm{FH}+, \mathrm{FH})$ as the between-subjects factor and time and medication as the within-subjects factors. Finally, to avoid multiple analyses, only those variables that showed significant naltrexone-related changes were used in Pearson correlations to examine the association between drug disposition 
and naltrexone-related changes in mood and neuroendocrine response.

\section{RESULTS}

\section{General Characteristics}

The major demographic and background data for the overall sample and the subgroups are summarized in Table 1 . The FH subgroups did not differ significantly on any of these demographic characteristics.

\section{HPA Axis Response}

Baseline levels $(t=0)$ of ACTH and cortisol were not significantly different between the naltrexone and placebo sessions (Figure 1). There was a declining slope in both hormones at the $30 \mathrm{~min}$ time point (9:30 A.M.) from baseline (9:00 A.M.), reflective of the normal diurnal pattern; this overall declining slope effect (Time: $\mathrm{F}_{7,112} \geqslant$ $2.11, p<.05)$ continued throughout the morning testing during the placebo session. Naltrexone significantly increased levels of both ACTH (Med: $\mathrm{F}_{1,16}=6.28, p<.05$ ) and cortisol (Med: $\mathrm{F}_{1,16}=6.45, p<.05$; see Figure 1). The elevations in ACTH levels after naltrexone were apparent by 60 through $120 \mathrm{~min}$ post-ingestion $(p<$ $.05)$, and for cortisol at $120 \mathrm{~min}(p<.05)$, with trends at 60, 90 and $180 \mathrm{~min}$ ( $p=.06$; simple effects tests). These data replicate prior studies, indicating oral naltrexone's disinhibition of the HPA axis, here in a larger sample of normal healthy subjects.

\section{Subjective Response}

Baseline levels for mood states were not significantly different between the naltrexone and placebo sessions.
Moreover, there were few significant mood changes after naltrexone administration compared with placebo. In the POMS, there was a significant naltrexone-related change on only one subscale, the Vigor scale (Med X Time: $\mathrm{F}_{2,32}=5.20, p<.05$ ), with naltrexone significantly decreasing vigor ratings at 90 and $240 \mathrm{~min}$ compared with baseline. There were no changes in ratings of alcohol-related urge, although several study parameters might have contributed to substantial floor effects for this particular variable (i.e., no alcohol cue, session conducted in the morning in a GCRC environment, and subjects were nonalcoholic social drinkers).

There was no difference between naltrexone and placebo in incidence of emerging side effects at the two points examined (90 and $240 \mathrm{~min}$ ). At $90 \mathrm{~min}, 12 \%$ of subjects endorsed one or more symptoms in the placebo session vs. $17 \%$ in the naltrexone session. At $240 \mathrm{~min}$, these percentages were $12 \%$ (placebo) and $28 \%$ (naltrexone) $\left(\chi^{2}=1.40, p=n s\right)$ and although statistically nonsignificant, these figures indicate a directional increase in the number of subjects reporting side effects four hours after naltrexone. All these symptoms were rated in the mild range and included: dizziness $(\mathrm{n}=2)$, flushed/ warm $(n=1)$, anxiety $(n=1)$, and erection $(n=1)$. The effects reported at the same time in the placebo session (240 min.) were sleepiness $(n=1)$ and headache $(n=1)$.

\section{FH Subgroup Analyses: HPA Axis and Subjective Response}

Examination of neuroendocrine changes as a function of FH revealed that the groups responded differently over time in terms of levels of both ACTH (FH X Time: $\left.\mathrm{F}_{7,77}=2.26, p<.05\right)$ and cortisol (FH X Time: $\mathrm{F}_{7,84}=$ $2.54, p<.05)$. The $\mathrm{FH}+$ group showed increases on these neuroendocrine parameters several hours after

Table 1. Demographic Characteristics for the Total Sample and FH Subgroups

\begin{tabular}{lccr}
\hline General Characteristics & $\begin{array}{c}\text { Total sample } \\
(\mathbf{n}=\mathbf{1 7})\end{array}$ & $\begin{array}{c}\text { Subgroup: } \\
\text { FH+ (n = 8) }\end{array}$ & $\begin{array}{r}\text { Subgroup: } \\
\text { FH- (n = 7) }\end{array}$ \\
\hline Age (years) & $33.9(2.0)$ & $31.0(2.2)$ & $36.1(3.0)$ \\
Education (years) & $14.7(0.4)$ & $14.5(0.9)$ & $14.6(0.5)$ \\
Height (cm) & $67.3(0.7)$ & $67.4(1.7)$ & $67.0(0.8)$ \\
Weight (kg) & $76.0(3.6)$ & $76.2(6.9)$ & $79.4(4.6)$ \\
Race (Caucasian /Afr American /Other) & $6 / 7 / 4$ & $4 / 3 / 1$ & $1 / 4 / 2$ \\
Gender (M/F) & $9 \mathrm{M} / 8 \mathrm{~F}$ & $5 \mathrm{M} / 3 \mathrm{~F}$ & $4 \mathrm{M} / 3 \mathrm{~F}$ \\
Alcohol consumption & & & \\
$\quad$ (drinks/occasion) & $2.4(0.4)$ & $2.6(0.9)$ & $2.1(0.5)$ \\
Alcohol frequency & & & \\
$\quad$ (occasions/week) & $1.4(0.4)$ & $1.8(0.8)$ & $1.0(0.4)$ \\
CAGE & $0.7(0.2)$ & $0.7(0.4)$ & $0.8(0.4)$ \\
MAST-10 & $0.4(0.2)$ & $0.4(0.7)$ & $0.4(0.3)$ \\
\hline
\end{tabular}

Note. Data indicate mean (SEM). Two subjects in overall sample excluded from family history analyses because they were of intermediate FH. Alcohol quantities based on standard drink conversions for 12 oz beer, $1.5 \mathrm{oz}$ liquor, and $5 \mathrm{oz}$ wine (=1 drink). MAST-10 = Michigan Alcoholism Screening Test (10 item version). 

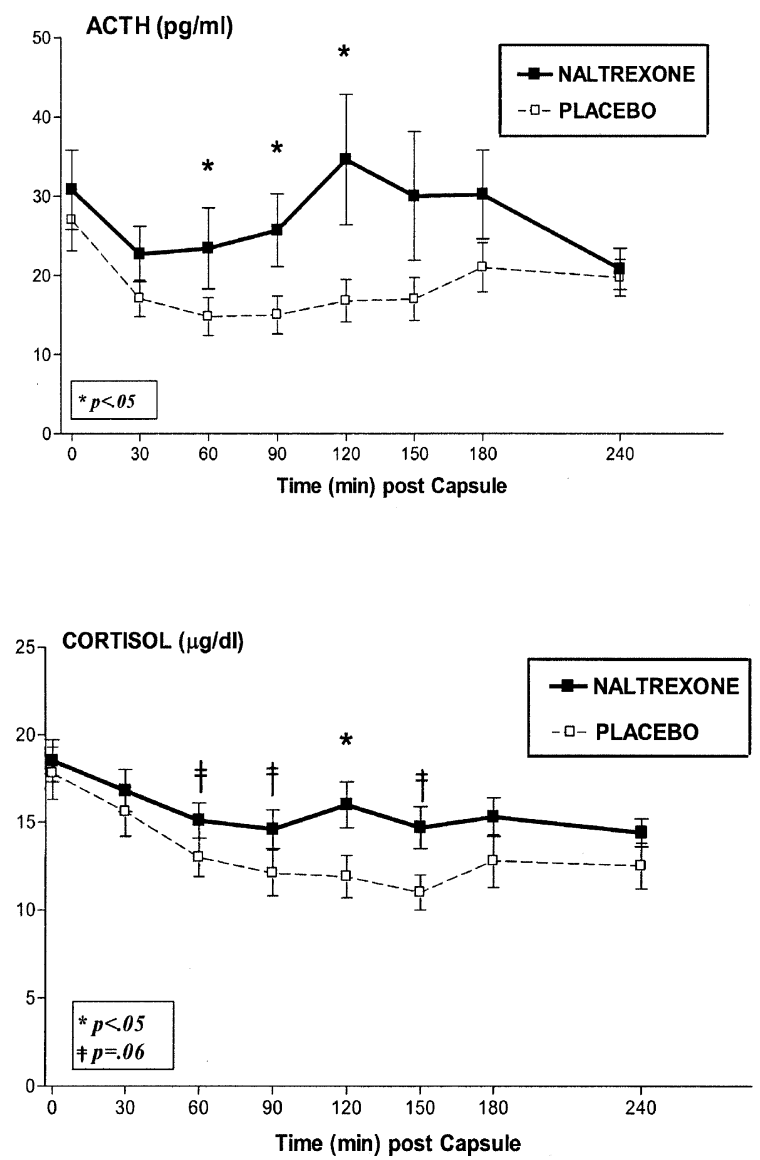

Figure 1. Overall sample $(n=18)$ ACTH and cortisol response to $50 \mathrm{mg}$ oral naltrexone. Naltrexone or placebo given immediately after the 0 time point. ${ }^{*} p<.05,{ }^{\ddagger} p=.06$ (simple effects tests).

medication administration whereas the $\mathrm{FH}$ - group did not show neuroendocrine changes over time (see Figure 2). The difference between $\mathrm{FH}+$ and $\mathrm{FH}-$ was particularly notable for cortisol: the $\mathrm{FH}-$ cortisol curves were nearly identical for the naltrexone and placebo sessions, reflective of the general diurnal decline during the morning, but the $\mathrm{FH}+$ group did not show the normal diurnal decline in cortisol during the naltrexone session (i.e., 90 through $240 \mathrm{~min}, p<.05$ ). A similar pattern was evident for ACTH, with naltrexone-induced increases for the $\mathrm{FH}+$ group (60 to $150 \mathrm{~min}, p<.05$ ) but not for the $\mathrm{FH}$ - group. However, considerable variability was noted in the $\mathrm{FH}+$ group and for both groups during the naltrexone session compared with placebo (see Figure 3), therefore indicating the importance of future investigations using larger subgroups of well-characterized subjects.

Group comparisons on mood effects revealed more sensitivity in $\mathrm{FH}+$ after naltrexone administration. The $\mathrm{FH}+$ group had greater decreases in ratings of POMS Vigor during their naltrexone compared with placebo session, in contrast to the $\mathrm{FH}-$ subjects who showed similar ratings of vigor across sessions (Med X FH: $\mathrm{F}_{1,13}=$ $5.69, p<.05)$. More side effects in general were reported by the $\mathrm{FH}+$ group (Main Effect Group: $\mathrm{F}_{1,13}=5.36, p<$ $.05)$ but there were no significant $\mathrm{FH}$ group differences in side effects due to naltrexone; as stated earlier, all adverse effects were rated in the mild range.

\section{Naltrexone Disposition}

Data for naltrexone biotransformation revealed, as expected, significant increases in naltrexone and 6- $\beta$-naltrexol levels over time (Time: $\mathrm{F}_{9,135} \geqslant 9.13, p<.0001$; see Figure 4). Levels of peak 6- $\beta$-naltrexol were approximately 10 times greater than naltrexone, which has been reported in past studies (Cone et al. 1974; King et al. 1997b; Verebey et al. 1976; Wall et al. 1981). Naltrexone levels in blood peaked at 60-120 min, and 6- $\beta$-naltrexol levels peaked $120 \mathrm{~min}$ after administration. There was a trend for an inverse relationship between levels of naltrexone and 6- $\beta$-naltrexol (180 $\mathrm{min},(r(15)=.45, p=$ $.08)$ ), suggesting rapid biotransformation of naltrexone to its major circulating metabolite in blood. Moreover, there was some suggestion of less rapid biotransformation of naltrexone to 6- $\beta$-naltrexol in $\mathrm{FH}+$ compared with $\mathrm{FH}$ - subjects, however these were not observed during peak levels, but rather in samples obtained after three hours of administration: lower naltrexone levels at $180 \mathrm{~min}$ in $\mathrm{FH}+$ and greater $6-\beta-$-naltrexol levels at 24 and $32 \mathrm{~h}$ post administration $(\mathrm{F}(1) \geqslant 4.62, p \leqslant .05)$.

Preliminary correlation analyses examined the relationship between extent of naltrexone metabolism (peak levels of naltrexone and 6- $\beta$-naltrexol) and peak changes in variables shown to have a significant naltrexonerelated change (ACTH, cortisol, and POMS Vigor). Results showed a significant positive relationship between peak serum naltrexone levels and peak ACTH $(r(15)=$ $+0.49, p=.05)$ and cortisol $(r(15)=+0.51, p<.05)$. Additionally, there was an inverse relationship between peak levels of 6- $\beta$-naltrexol and ACTH $(r(15)=-0.58$, $p=.02)$. There were no significant correlations between these variables and subjective response, i.e., POMS Vigor ratings $(r(15) \geqslant-.32, p=\mathrm{ns})$.

\section{DISCUSSION}

The results of the present study, showing acute ACTH and cortisol elevations $60-150 \mathrm{~min}$ after a single oral dose of $50 \mathrm{mg}$ naltrexone, extend prior studies demonstrating similar neuroendocrine increases after intravenous naloxone infusion. Naloxone-induced alterations in the opioidergic modulation of HPA activity, demonstrated in numerous studies in the past 10-15 years, have been assumed to extend to oral naltrexone, the only available opioid antagonist approved for clinical treatment of opioid and alcohol dependence. Naltrex- 

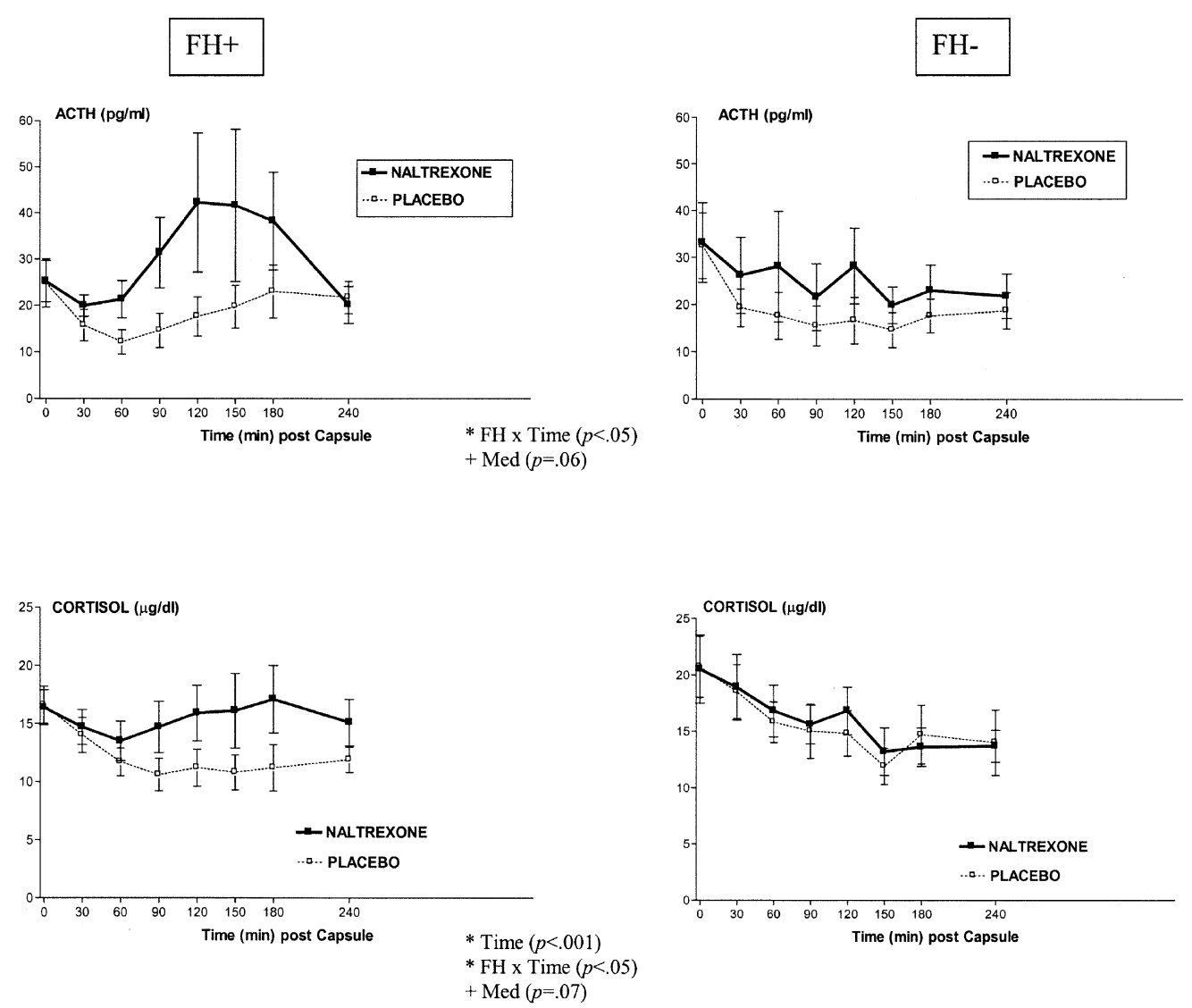

Figure 2. $\mathrm{FH}+$ and $\mathrm{FH}-$ subgroup $\mathrm{ACTH}$ and cortisol response to $50 \mathrm{mg}$ oral naltrexone. Naltrexone or placebo given immediately after the 0 time point.

one, a primarily $\mu$-receptor antagonist but also acting on $\delta$ and $\kappa$ receptors, undergoes extensive first-pass metabolism and biotransformation and has not been studied as broadly as naloxone in terms of acute neuroendocrine and physiological mechanisms. Although the sample size in the present study was relatively modest, it exceeded the sample sizes in the two previous published studies of HPA response to naltrexone (Farren et al. 1999; Volavka et al. 1979b) and the results showed reliable and steady increases in ACTH and cortisol levels within two hours of administration. Following the acute peak increases in pituitary- and adrenal-derived $\mathrm{ACTH}$ and cortisol, respectively, there were slow declines over the next several hours, which is a likely result of the inherent negative feedback loops involved in normal regulation of the HPA axis. It remains to be determined whether these acute elevations may persist in those persons in either intermediate- or long-term treatment of naltrexone for treatment of alcohol dependence, as has been shown in persons with chronic heroin addiction on naltrexone maintenance (Kosten et al. 1986a,b).

Although orally administered naltrexone undergoes extensive first-pass metabolism, the biotransformation of naltrexone to its major metabolite, 6- $\beta$-naltrexol, showed a similar time course to the HPA changes observed, with peak serum levels of both compounds occurring approximately two hours after administration. Moreover, there was a significant positive association between peak serum naltrexone levels and ACTH and cortisol levels and an inverse relationship between peak serum 6- $\beta$-naltrexol and ACTH levels. These related associations suggest that heightened HPA response to naltrexone might be a direct effect of opioid antagonism on hypothalamic-pituitary hormone release and not due to a nonspecific effect. Although the present study used only a single oral dose of $50 \mathrm{mg}$ naltrexone, the findings indicate that extent of naltrexone biotransformation is associated with extent of opioid-induced modulation of the HPA axis. Further, although in this study and in other studies, levels of 6 - $\beta$-naltrexol exceeded those of naltrexone within a few hours after administration, the relationship of naltrexone to HPA axis hormone levels suggest that naltrexone is the main pharmacologically active component blocking opioid receptors involved in HPA regulation. In contrast, 6 - $\beta$-naltrexol is a much less potent opioid antagonist (Cone et al. 1974; Fujimoto et al. 1975). However, 

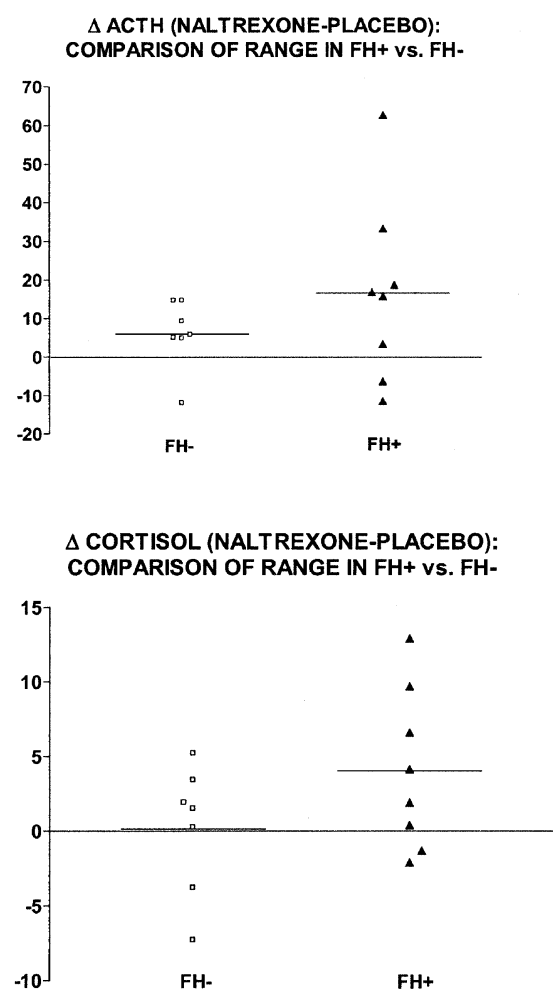

Figure 3. $\mathrm{FH}+$ and $\mathrm{FH}-$ change in $\mathrm{ACTH}$ and cortisol response ( $\Delta$ Naltrexone - Placebo) at the first point the groups show divergent response, i.e., 90 min after administration. Point plot shows the large variability in response for both groups.

6- $\beta$-naltrexol may contribute significantly to the side effects observed during acute alcohol administration (King et al. 1997a), reduced alcohol liking, and/or general sedation (McCaul et al. 2000). Further studies in larger samples should help to further characterize the effects of opioidergic blockade and biotransformation factors on hypothalamic-derived stress response in persons with and without alcohol dependence.

Subjects reported few acute naltrexone-induced subjective side effects or mood changes, apart from decreases in self-reported vigor over time, in contrast to prior reports suggesting greater acute subjective effects in acute paradigms (King et al. 1997a; Mendelson et al. 1978) or during repeated naltrexone dosing in clinical trials (Kranzler et al. 2000; McCaul et al. 2000). The decreased ratings for POMS Vigor and the mild side effects, observed in several subjects in this study, such as dizziness, headache, erections, and anxiety were not associated with drug disposition or neuroendocrine changes, suggesting that these symptoms are independent of the extent of biotransformation or the opioidergic-hypothalamic system and may be nonspecific effects. The difference between the present study, showing few marked mood changes after oral naltrexone, and prior studies indicating nausea and other unpleasant effects

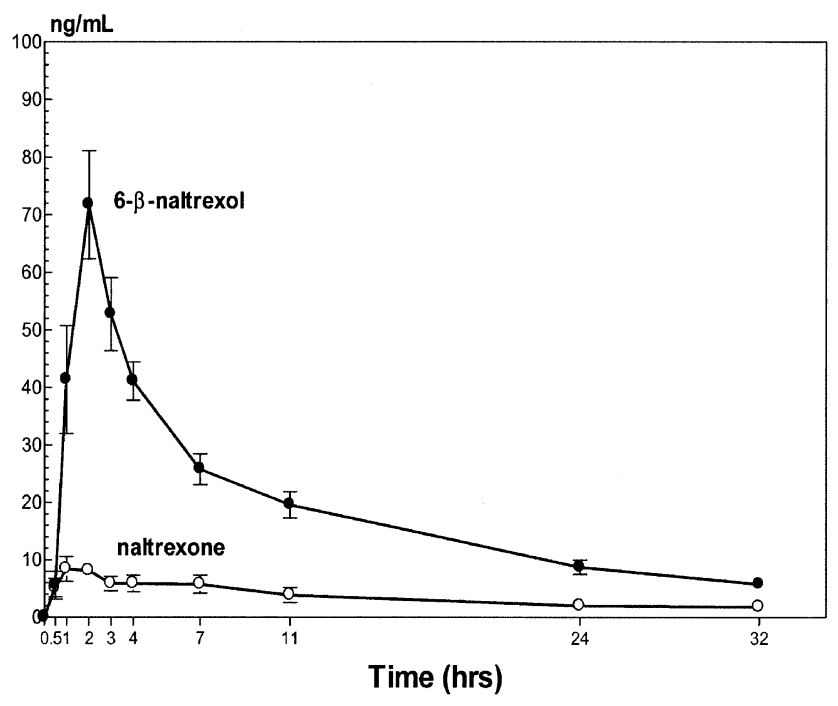

Figure 4. Naltrexone and 6- $\beta$-naltrexol levels after administration (time 0 ) for the total sample.

may be due to several study parameters. For example, our subjects consumed two light meals during the course of the study and were tested in a stress-minimized environment (i.e., a bed or comfortable chair in a private room in the CRC), while in some other studies, the incidents of headache, nausea, and/or vomiting often occurred or were exacerbated after consumption of alcohol (Davidson et al. 1996; King et al. 1997b; McCaul et al. 2000; Swift et al. 1994) and not after single administration of the active drug. Therefore, it is possible that the discrepancy may be due to study differences in time course of subjective report (i.e., immediate versus retrospective), interactive effects with alcohol consumption, and potential uncontrolled environmental influences.

Prior studies have shown that high-risk individuals, by virtue of a positive biological family history of alcoholism, show alterations in HPA axis response to a variety of behavioral and physiological agents (Peterson et al. 1996; Gianoulakis et al. 1996; King et al. 1998; Schuckit et al. 1988, 1996; Waltman et al. 1994). Also, several recent studies have demonstrated that opioidergic hypothalamic sensitivity is greater in high-risk, $\mathrm{FH}+$ persons (Wand et al. 1998, 2001) and may vary as a function of gender (Wand et al. 1999a) and degree of obsessive-compulsive symptomatology (Mangold et al. 2000). Circadian rhythmicity of cortisol has been found to be similar in $\mathrm{FH}+$ and $\mathrm{FH}-$ groups, as well as responses to direct adrenal gland provocation (Wand et al. 1999b). Therefore, there is mounting evidence in human studies that the cortisol and ACTH elevations from intravenous opioid antagonism with naloxone, and now in the present study with oral naltrexone, result from direct opioid antagonist disinhibition at the level of the central nervous system. Other reports have suggested 
that the arcuate nucleus neurons containing $\beta$-endorphin and pro-enkephalin regulate hypothalamic CRF and thus pituitary- and adrenal-derived stress hormones (see Wand et al. 1998, 1999a,b). The arcuate nucleus also has connections to the nucleus accumbens and mesolimbic dopamine regulatory systems. Therefore, in addition to the direct effects of CRF and related hormones theorized to be involved in alcohol and drug dependence (Koob 1999), the pathways to the dopaminergic system may represent another important endogenous opioid system link to heightened vulnerability to addiction. We may speculate that those persons with $\mathrm{FH}+$, at presumed greater risk for future alcoholism, have inherent lower opioid tone and therefore greater acute response to perturbations in this stress-responsive modulation of the HPA axis. However, an alternative hypothesis, that these opioid-sensitive responses are not premorbid but acquired or interact with environmental influences in at-risk persons cannot be ruled out at present and may be further examined in well-controlled animal studies.

Finally, although our sample was small, we demonstrated these findings in a more racially diverse $(60 \%$ non-Caucasian in the present study vs. $15 \%$ in other studies) and older (mean age 33 yrs vs. 21 yrs) group of participants than in many previous studies (Wand et al. 1998, 1999a,b; Mangold et al. 2000), thereby increasing the generalizability of these neuroendocrine effects to more representative samples. In addition to HPA axis differences, we also showed enhanced $\mathrm{FH}+$ sensitivity to naltrexone in terms of greater mood response, i.e., significant decreases in vigor ratings, which were not present in the $\mathrm{FH}-$ group. However, the small subgroup sizes in the present study limit the power of the statistical analyses performed in the secondary analyses. It will be important to continue such studies with larger sample sizes to further characterize potential differences in response to oral naltrexone due to family history of alcoholism. In addition, more rigorous methods for FH determination, including obtaining verification from a collateral family member, is suggested for future studies. It will also be of interest in future studies to determine whether any differences in response to oral naltrexone, such as those alluded to in this report with $\mathrm{FH}+$ persons, might be related to the presence of a heterozygous or homozygous state with respect to a very common allelic variant of the $\mu$-opioid receptor gene A118G. This variant has been found by our group, in collaboration with the group of Dr. Lei Yu, to have both significantly greater binding and functional responses to the longest endogenous opioid, $\beta$-endorphin, than does the prototype or usual gene product (Bond et al. 1998; Kreek 2000; LaForge et al. 2000).

In summary, this paper extends previously documented ACTH and cortisol elevations after naloxone infusion, to orally administered naltrexone. The Findings also reinforce the link between the endogenous opioid system and the HPA axis. The HPA axis, typically examined through levels of ACTH and/or $\beta$ endorphin from the pituitary gland and cortisol from the adrenal gland, is indicative of a stress-responsive system, in part under modulation by opioid tone in addition to glucocorticoid negative feedback inhibition. Perturbations in the HPA axis state of activation may or may not be related to alcohol and other substances of abuse related reward (O'Malley et al. 2001). Another significant finding in the present study was that levels of naltrexone in blood were significantly associated with ACTH and cortisol levels, suggesting that naltrexone, and not $6-\beta$-naltrexol, may be the biologically active component responsible for opioid antagonist disinhibition of centrally-mediated HPA axis sensitivity. Finally, we also added support to prior studies indicating the potential biological bases of altered opioidergic sensitivity in those persons with an assumed greater inherited vulnerability for future alcoholism $(\mathrm{FH}+)$. Intermediate- and long-term studies are needed in order to determine whether these effects may be predictive of treatment compliance (Volpicelli et al. 1997), clinical response to oral naltrexone, and the mechanisms of risk and biological bases of addictive disorders.

\section{ACKNOWLEDGMENTS}

This work was supported by NIH (K05 DA-00049 (MJK), P50 DA05130, R03 AA11001, R03 AA11133 (AK), and M01-RR-00102). The assistance of Irahisa Disla and the staff of the Rockefeller University GCRC is greatly appreciated.

\section{REFERENCES}

Anton RF, Moak DH, Waid LR, Latham PK, Malcolm RJ, Dias JK (1999): Naltrexone and cognitive behavioral therapy for the treatment of outpatient alcoholics: results of a placebo-controlled trial. Am J Psychiatry 156:1758-1764

Bohn MJ, Krahn DD, Staehler BA (1995): Development and initial validation of a measure of drinking urges in abstinent alcoholics. Alcohol Clin Exp Res 19:600-606

Bond C, LaForge KS, Tian M, Melia D, Zhang S, Borg L, Gong J, Schluger J, Strong JA, Leal SM, Tischfield JA, Kreek MJ, Yu L (1998): Single nucleotide polymorphism in the human mu opioid receptor gene alters betaendorphin binding and activity: Possible implications for opiate addiction. Proc Natl Acad Sci 95: 9608-9613

Cahalan V, Cisin I, Crossley HM (1969): American Drinking Practices. New Jersey, Rutgers Center for Alcohol Studies

Cohen MR, Cohen RM, Pickar D, Weingartner H, Murphy DL (1983): High-dose naloxone infusion in normals. Arch Gen Psychiatry 40:613-619

Conaglen JV, Donald RA, Espiner EA, Livesey JH, Nicholls MG (1985): Effect of naloxone on the hormone response to CRF in normal man. Endocr Res 11:39-44

Cone EJ, Gorodetzky CW, Yeh SY (1974): The urinary excre- 
tion profiles of naltrexone in man. Drug Metab Dispos 2:506-512

Cushman P, Kreek MJ (1974): Some endocrinologic observations in narcotic addicts. In Zimmerman E, George $\mathrm{R}$ (eds), Narcotic and the Hypothalamus. New York, Raven Press, pp 161-173.

Davidson D, Swift R, Fitz E (1996): Naltrexone increases the latency to drink alcohol in social drinkers. Alcoholism: Clinical and Experimental Research 20:732-9

Delitala G, Trainer PJ, Fanciulli G, Grossman AB (1994): Opioid peptide and $\alpha$-adrenoceptor pathways in the regulation of the pituitary-adrenal axis in man. J Endocrinol 141:163-168

Ewing JA (1984): Detecting alcoholism: The CAGE questionnaire. JAMA 252:1905-1907

Farren C, O'Malley S, Grebski G, Maniar S, Porter M, Kreek MJ (1999): Variable dose naltrexone-induced hypothalamic-pituitary-adrenal stimulation in abstinent alcoholics: A preliminary study. Alcohol Clin Exp Res 23:502-508

First MB, Spitzer RL, Gibbon M, Williams JBW (1995): Structured Clinical Interview for DSM-IC Axis I Disorders Patient Edition (SCID-I/P, Version 2.0). New York, Biometrics Research Department

Fujimoto JM, Roerig S, Wang RI, Chatterjie N, Inturrisi CE (1975): Narcotic antagonistic activity of several metabolites of naloxone and naltrexone testing in morphine dependent mice. Proc Soc Exp Biol Med 148:443-448

Gianoulakis C, Beliveau D, Angelogianni P, Meaney M, Thavundayil J, Tawar V, Dumas M (1989): Different pituitary $\beta$-endorphin and adrenal cortisol response to ethanol in individuals with high and low risk for future development of alcoholism. Life Sci 45:1097-1109

Gianoulakis C, Krishnan B, Thavundayil J (1996): Enhanced sensitivity of pituitary $\beta$-endorphin to ethanol in subjects at high risk of alcoholism. Arch Gen Psychiatry 53: 250-257

Gonzalez JP, Brogden RN (1988): Naltrexone: A review of its pharmacodynamic and pharmacokinetic properties and therapeutic efficacy in the management of opioid dependence. Drugs 35:192-213

Heatherington TF, Kozlowski LT, Frecker RC, Fagerström KO (1991): The Fagerström Test for nicotine dependence: a revision of the Fagerström tolerance questionnaire. Br J Addict 86:1119-1127

Johnson EO, Kamilaris TC, Chrousos GP, Gold PW (1992): Mechanisms of stress: a dynamic overview of hormonal and behavioral homeostasis. Neurosci Biobehav Rev 16: 115-130

King AC, Schluger, J, Disla I, Kreek MJ (1998): Acute neuroendocrine effects of oral naltrexone in family history positive and negative social drinkers. Alcoholism: Clinical and Experimental Research 22: 120A

King AC, Volpicelli JR, Gunduz M, O’Brien CP, Kreek MJ (1997a): Naltrexone biotransformation and incidence of subjective side effects: a preliminary study. Alcohol Clin Exp Res 21:906-909

King AC, Volpicelli JR, Frazer A, O’Brien CP (1997b): Effect of naltrexone on subjective alcohol response in subjects at high and low risk for future alcohol dependence. Psychopharmacology 129: 15-22

Koob GF (1999): Stress, corticotropin-releasing factor, and drug addiction. Ann N Y Acad Sci 897:27-45
Kosten TR, Kreek MJ, Raghunath J, Kleber HD (1986a): Cortisol levels during chronic naltrexone maintenance treatment in ex-opiate addicts. Biol Psych 21:217-220

Kosten TR, Kreek MJ, Raghunath J, Kleber HD (1986b): A preliminary study of beta-endorphin during chronic naltrexone maintenance treatment in ex-opiate addicts. Life Sci 39:55-59

Kranzler HR, Modesto-Lowe V, Van Kirk J (2000): Naltrexone vs. nefazodone for treatment of alcohol dependence: a placebo-controlled study. Neuropsychopharmacology 22:493-503

Kreek MJ (1972): Medical safety, side effects, and toxicity of methadone. Proceedings of the Fourth National Conference on Methadone Treatment, National Association for the Prevention of Addiction to Narcotics, New York, pp 171-174

Kreek MJ (1973): Physiological implications of methadone treatment. Proceedings of the Fifth National Conference of Methadone Treatment. National Association for the Prevention of Addiction to Narcotics, pp 85-91

Kreek MJ (1978): Medical complications in methadone patients. Ann NY Acad Sci 311:110-134

Kreek MJ (1992): Rationale for maintenance pharmacotherapy of opiate dependence. In $\mathrm{O}^{\prime}$ Brien $\mathrm{CP}$, Jaffe JH (eds), Addictive States. Association for Research in Nervous and Mental Disease, Vol. 70. New York, Raven Press, pp 205-230

Kreek MJ (2000): Opiates, opioids, SNPs and the addictions: Nathan B. Eddy Memorial Award for lifetime excellence in drug abuse research lecture. In Harris LS (ed), Problems of Drug Dependence, 1999; Proceedings of the 61st Annual Scientific Meeting of the College on Problems of Drug Dependence. National Institute of Drug Abuse Research Monogaph Series. Washington, D.C.: Supt. of Docs., U.S. Govt. Print. Off., DHHD Pub. No. (ADM)00-4737, 180:3:22

Kreek MJ, Raghunath J, Plevy S, Hamer D, Schneder B, Hartman N (1984): ACTH, cortisol, and beta-endorphin response to metyrapone testing during chronic methadone maintenance treatment in humans. Neuropeptides 5:277-278

Kreek MJ, Schneder BS, Raghunath J, Plevy S (1984): Prolonged (24 hour) infusion of the opioid antagonist naloxone does not significantly alter plasma levels of cortisol and ACTH in humans. Abstracts of the seventh international congress of endocrinology, Excerpta Medica, International congress series 652, Amsterdam-OxfordPrinceton: 845

LaForge KS, Shick V, Spangler R, Proudnikov V, Lysov Y, Mirzabekov A, Kreek MJ (2000): Detection of single nucleotide polymorphisms of the human mu opioid receptor gene by hybridization or single nucleotide extension on custom oligonucleotide gelpad microchips: Potential in studies of addiction. Neuropsychiatric Genetics 96:604-615

Levenson RW, Oyama ON, Meek PS (1987): Greater reinforcement from alcohol for those at risk: parental risk, personality risk, and gender. J Abnorm Psychol 96:242-253

Mangold DL, Peyrot M, Giggey P, Wand GS (2000): Endogenous opioid activity is associated with obsessive-compulsive symptomology in individuals with a family history of alcoholism. Neuropsychopharmacology 22:595-607 
Martin del Campo AE, Dowson JH, Herbert J, Paykel ES (1994): Effects of naloxone on diurnal rhythms in mood and endocrine function: a dose-response study in man. Psychopharmacology (Berl) 114:583-590

McCaul ME, Wand GS, Rohde C, Lee SM (2000): Serum 6-beta-naltrexol levels are related to alcohol responses in heavy drinkers. Alcohol Clin Exp Res 24:1385-1391

McNair DM, Lorr M, Droppleman LF (1971): Manual for the Profile of Mood States. San Diego, Educational and Industrial Testing Service

Mendelson JH, Ellingboe J, Keuhnle JC, Mello NK (1978): Effects of naltrexone on mood and neuroendocrine function in normal adult males. Psychoneuroendocrinology 3:231-236

Morley J, Baranetsky NG, Wingert TW, Carleson HE, Hershman JM, Melmed S, Levin SR, Jamison KR, Weitzman R, Chang J, Varner AA (1980): Endocrine effects of naloxone-induced opiate receptor blockade. J Clin Endocrinol Metab 50: 251-257

Naber D, Pickar D, Davis GC, Cohen RM, Jimerson DC, Elchisak MA, Defraites EG, Kalin NH, Risch SC, Buchsbaum MS (1981): Naloxone effects on b-endorphin, cortisol, prolactin, growth hormone, HVA, MHPG, in plasma of normal volunteers. Psychopharmacol 74:125-128

O'Malley SS, Krishnan-Sarin S, Farren C, Sinha R, Kreek MJ (2001): Naltrexone decreases craving and alcohol selfadministration in alcohol dependent subjects and activates the hypothalamo-pituitary-adrenocorticol axis. Psychopharmacol (In press)

O'Malley SS, Carey KB, Maisto SA (1986): Validity of young adults' reports of parental drinking practices. J Stud Alcohol 47:433-435

O'Malley SS, Jaffe A, Chang G, Shottenfeld RS, Meyer RE, Rounsaville B (1992): Naltexone and coping skills therapy for alcohol dependence: a controlled study. Arch Gen Psych 49: 881-887

Peterson JB, Pihl RO, Gianoulakis C, Conrod P, Finn PR, Stewart SH, LeMarquand DG, Bruce KR (1996): Ethanol-induced change in cardiac and endogenous opiate function and risk for alcoholism. Alcohol Clin Exp Res 20:1542-1552

Pokorny AD, Miller BA, Kaplan HB (1972): The brief MAST: a shortened version of the Michigan alcoholism screening test. Am J Psychiatry 129:342-345

Schacham S (1983): A shortened version of the profile of mood states. J Pers Assess 47:305-306

Schluger J, Ho A, Porter M, Maniar S, Gunduz M, Perret G, King A, Kreek MJ (1998): Nalmefene causes greater hypothalamic-pituitary-adrenal axis activation than naloxone in normal volunteers: implications for the treatment of alcoholism. Alcohol Clin Exp Res 22:1430-1436

Schuckit MA, Gold EO (1988): A simultaneous evaluation of multiple markers of ethanol/placebo challenges in sons of alcoholics and controls. Arch Gen Psych 45:211-216
Schuckit MA, Gold E, Risch C (1987): Plasma cortisol levels following ethanol in sons of alcoholics and controls. Arch Gen Psych 44:942-945

Schuckit MA, Risch SC, Gold EO (1988): Alcohol consumption, ACTH level, and family history of alcoholism. Amer J Psychiatry 145:1391-1395

Schuckit MA, Tsuang JW, Anthenelli RM, Tipp JE, Nurnberger JI (1996): Alcohol challenges in young men from alcoholic pedigrees and control families: A report from the COGA project. J Stud Alc 57:368-377

Sher KJ, Descutner C (1986): Reports of paternal alcoholism: reliability across siblings. Addict Behav 11:25-30

Swift RM, Whelihan W, Kuznetsov O, Buongiorno G, Hsuing $H$ (1994): Naltrexone-induced alterations in human ethanol intoxication. Americal Journal of Psychiatry 151:1463-1467

Verebey K, Volavka J, Mule SJ, Resnick RB (1976): Naltrexone: disposition, metabolism, and effects after acute and chronic dosing. Clin Pharmacol Ther 20:315-328

Volavka J, Cho D, Mallya A, Bauman J (1979a): Naloxone increases ACTH and cortisol levels in man. N Engl J Med 300:1056-1057

Volavka J, Mallya A, Bauman J, Pevnick J, Cho D, Reker D, James B Dornbush (1979b): Hormonal and other effects of naltrexone in normal men. Adv Exp Med Biol

Volpicelli JR, Alterman AI, Hayashida M, O’Brien CP (1992): Naltrexone in the treatment of alcohol dependence. Arch Gen Psychiatry 49:876-880

Volpicelli J, Rhines KC, Rhines JS, Volpicelli PA, Alterman Ai, O'Brien CP (1997): Naltrexone and alcohol dependence: role of subject compliance. Arch Gen Psychiatry 54:737-742

Wall ME, Brine DR, Perez-Reyes M (1981): Metabolism and disposition of naltrexone in man after oral and intravenous administration. Drug Metab Dispos 9:369-375

Wand GS, Mangold D, El Deiry S, McCaul ME, Hoover D (1998): Family history of alcoholism and hypothalamic opioidergic activity. Arch Gen Psychiatry 55:1114-1119

Wand GS, Mangold D, Ali M (1999a): Adrenocorticotropin responses to naloxone in sons of alcohol-dependent men. J Clin Endocrinol Metab 84:64-68

Wand GS, Mangold D, Ali M, Giggey P (1999b): Adrenocortical responses and family history of alcoholism. Alcohol Clin Exp Res 23:1185-1190

Wand GS, McCaul ME, Gotjen D, Reynolds J, Lee S (2001): Confirmation that offspring from families with alcoholdependent individuals have greater hypothalamic-pituitary-adrenal axis activation induced by naloxone compared with offspring without a family history of alcohol dependence. Alcohol Clin Exp Res 25:1134-1139

Waltman C, McCaul B, Wand GS (1994): Adrenocorticotropin responses following administration of ethanol and ovine corticotropin-releasing hormone in the sons of alcoholics and controls subjects. Alcohol Clin Exp Res $18: 826-830$ 